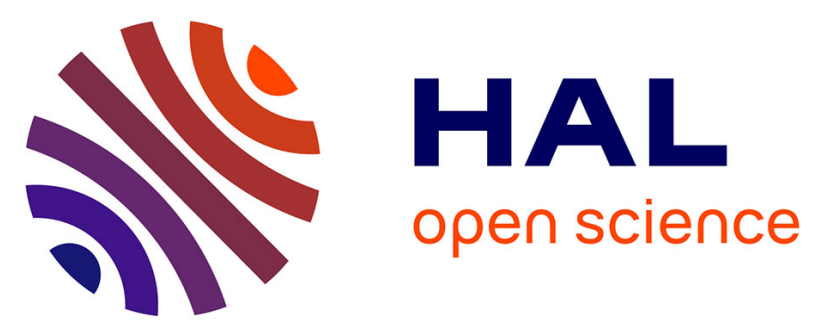

\title{
An association between maternal weight change in the year before pregnancy and infant birth weight: ELFE, a French national birth cohort study
}

Marion Lecorguillé, Madalina Jacota, Blandine de Lauzon-Guillain, Anne Forhan, Marie Cheminat, Marie-Aline Charles, Barbara Heude

\section{To cite this version:}

Marion Lecorguillé, Madalina Jacota, Blandine de Lauzon-Guillain, Anne Forhan, Marie Cheminat, et al.. An association between maternal weight change in the year before pregnancy and infant birth weight: ELFE, a French national birth cohort study. PLoS Medicine, 2019, 16 (8), pp.e1002871. 10.1371/journal.pmed.1002871 . inserm-02273886

\section{HAL Id: inserm-02273886 https://www.hal.inserm.fr/inserm-02273886}

Submitted on 29 Aug 2019

HAL is a multi-disciplinary open access archive for the deposit and dissemination of scientific research documents, whether they are published or not. The documents may come from teaching and research institutions in France or abroad, or from public or private research centers.
L'archive ouverte pluridisciplinaire HAL, est destinée au dépôt et à la diffusion de documents scientifiques de niveau recherche, publiés ou non, émanant des établissements d'enseignement et de recherche français ou étrangers, des laboratoires publics ou privés. 


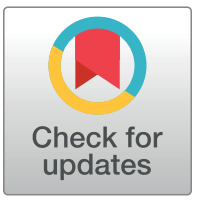

\section{OPEN ACCESS}

Citation: Lecorguillé $M$, Jacota M, de LauzonGuillain B, Forhan A, Cheminat M, Charles M-A, et al. (2019) An association between maternal weight change in the year before pregnancy and infant birth weight: ELFE, a French national birth cohort study. PLoS Med 16(8): e1002871. https://doi.org/ 10.1371/journal.pmed.1002871

Academic Editor: Kathleen Rasmussen, Cornell University, UNITED STATES

Received: March 6, 2019

Accepted: July 17, 2019

Published: August 20, 2019

Copyright: @ 2019 Lecorguillé et al. This is an open access article distributed under the terms of the Creative Commons Attribution License, which permits unrestricted use, distribution, and reproduction in any medium, provided the original author and source are credited.

Data Availability Statement: Data cannot be shared publicly to conform with the EU General Data Protection regulation. Data are available from the ELFE Institutional Data Access / Ethics Committee (contact via https://www.elfe-france.fr/ en/the-research/access-to-data-andquestionnaires/) for researchers who meet the criteria for access to confidential data.

Funding: $\mathrm{ML}$ received the $\mathrm{PhD}$ contract by the University Paris Descartes for this research. The
RESEARCH ARTICLE

\section{An association between maternal weight change in the year before pregnancy and infant birth weight: ELFE, a French national birth cohort study}

\author{
Marion Lecorguillé ${ }^{1}{ }^{*}$, Madalina Jacota ${ }^{2}$, Blandine de Lauzon-Guillain ${ }^{1}{ }^{1}$, Anne Forhan ${ }^{1}$, \\ Marie Cheminat ${ }^{3}$, Marie-Aline Charles $\mathbb{D}^{1,3 \ddagger}$, Barbara Heude $\mathbb{D}^{1 \neq}$ \\ 1 Université de Paris, Centre of Research in Epidemiology and Statistics, INSERM, Institut national de la \\ recherche agronomique, Paris, France, 2 APHP, Unité de Recherche Clinique, Hôpitaux Universitaires Paris \\ île-de-France Ouest, Paris, France, 3 Institut national d'études démographiques, INSERM, Établissement \\ français du sang, Joint Unit Elfe, Paris, France \\ $\ddagger$ These authors are joint senior authors on this work. \\ * marion.lecorguille@inserm.fr
}

\section{Abstract}

\section{Background}

Weight-control interventions in pregnant women with overweight or obesity have limited effectiveness for fetal growth and birth outcomes. Interventions or prevention programs aiming at the pre-pregnancy period should be considered. However, how the woman's weight change before pregnancy affects fetal growth is not known. We investigated the association between weight change over the year before pregnancy and birth weight.

\section{Methods and findings}

We used the inclusion data of 16,395 women from the ELFE French national birth cohort, a nationally representative cohort in which infants were enrolled at birth with their families in 2011. Maternal weight change was self-reported and classified into 3 groups: moderate weight variation or stable weight, weight loss $>5 \mathrm{~kg}$, and weight gain $>5 \mathrm{~kg}$ or both weight loss and gain $>5 \mathrm{~kg}$. Multiple linear regression models were used to investigate the association between pre-pregnancy weight change and a birth weight $z$-score calculated according to the French Audipog reference, adjusted for a large set of maternal characteristics. The analyses were stratified by maternal body mass index (BMI) at conception ( $<25$ versus $\geq 25$ $\mathrm{kg} / \mathrm{m}^{2}$ ) and adjusted for BMI within these categories. We used the MacKinnon method to test the mediating effect of gestational weight gain (GWG) on these associations. Mother's mean age was 30.5 years, $87 \%$ were born in France, and $26 \%$ had overweight or obesity. For women in either BMI category at conception, GWG was more than $2 \mathrm{~kg}$ higher, on average, for women with weight loss before pregnancy than for women with stable weight or moderate weight variation. For women with $\mathrm{BMl}<25 \mathrm{~kg} / \mathrm{m}^{2}$ at conception, birth weight was significantly higher with weight loss than stable weight before pregnancy $(\beta=0.08[95 \% \mathrm{Cl}$ $0.02 ; 0.14], p=0.01$ ), and this total effect was explained by a significant mediating effect 
funder had no role in study design, data collection and analysis, decision to publish, or preparation of the manuscript.

Competing interests: The authors have declared that no competing interests exist.

Abbreviations: BMI, body mass index; GWG, gestational weight gain; LGA, large for gestational age; SGA, small for gestational age. through GWG. For women with $\mathrm{BMI} \geq 25 \mathrm{~kg} / \mathrm{m}^{2}$ at conception, birth weight was not associated with pre-pregnancy weight loss during the year before pregnancy. Mediation analysis revealed that in these women, the direct effect of pre-pregnancy weight loss that would have resulted in a smaller birth weight $z$-score $(\beta=-0.11$ [95\% $\mathrm{Cl}-0.19 ;-0.03], p=0.01)$ was cancelled out by the GWG. The mediating effect of GWG was even higher when weight loss resulted from a restrictive diet in the year before pregnancy. Weight gain before pregnancy was not associated with birth weight. Although we included a large number of women and had extensive data, the only potential cause of pre-pregnancy weight loss that was investigated was dieting for intentional weight loss. We have no information on other potential causes but did however exclude women with a history of pre-pregnancy chronic disease. Another limitation is declaration bias due to self-reported data.

\section{Conclusions}

Health professionals should be aware that GWG may offset the expected effect of weight loss before conception on fetal growth in overweight and obese women. Further studies are required to understand the underlying mechanisms in order to develop weight-control interventions and improve maternal periconceptional health and developmental conditions for the fetus.

\section{Author summary}

\section{Why was this study done?}

- Maternal obesity is associated with macrosomia at birth and long-term health consequences for the offspring.

- Results from weight-control interventions during pregnancy suggest that it is too late to address obesity consequences once the pregnancy has already started and that more attention should be paid to the preconception period.

- The impact of maternal weight changes before pregnancy on infant birth weight has not been thoroughly investigated.

\section{What did the researchers do and find?}

- We assessed the association between maternal reported weight changes during the year before pregnancy and infant birth weight in the ELFE French national birth cohort.

- For women with overweight and obesity, weight loss before pregnancy was associated with increased gestational weight gain compared to women with stable weight before pregnancy, which seemed to cancel out an expected reduction of infant birth weight. 


\section{What do these findings mean?}

- For women with overweight and obesity, weight-control interventions before pregnancy could be beneficial for fetal growth. Health professionals should be aware of a potential weight gain rebound during pregnancy after a weight loss before pregnancy.

- Further studies are required to understand the role of weight changes in the preconception period in order to refine nutritional prevention messages for women of childbearing age.

\section{Introduction}

Reducing adverse pregnancy and fetal outcomes for women with overweight and obesity is a public health priority. Maternal obesity is a risk factor for maternal complications during pregnancy and for infants being large for gestational age (LGA) [1-3]. Also, maternal obesity during pregnancy has been associated with long-term health consequences for the offspring, such as increased body mass index (BMI) during infancy, childhood, and later life and increased risk of type 2 diabetes in adulthood [4,5]. Excessive gestational weight gain (GWG) can also contribute to increased risk of poor maternal and birth outcomes [1,6]. The Institute of Medicine recommends GWG ranges during pregnancy, according to pre-pregnancy BMI category, that are associated with good maternal and infant outcomes $[7,8]$.

Some interventions to prevent or reduce obesity and its consequences have been implemented during the pregnancy period [9]. Lifestyle interventions during pregnancy could reduce GWG [10]. However, further studies have suggested that for women with overweight and obesity, diet and lifestyle interventions during pregnancy have very limited impact on other pregnancy outcomes, birth weight, and overweight risk in offspring [11-13]. These results are consistent with those from observational studies showing that high BMI before pregnancy was a stronger predictor of the risk of LGA than was excessive GWG [14]. Altogether, these results suggest that it is too late to address obesity consequences once the pregnancy has already started and that more attention should be paid to the preconception period.

The periconception period may represent a critical window during which nutritional exposure can influence embryo development and risk of obesity in the offspring. Similar maternal weight status at the start of pregnancy may result from distinct weight trajectories before pregnancy, which reflect particular nutritional and metabolic states. Different dynamics in preconception weight could specifically influence fetal growth and play a distinct role from the effect of nutritional stores during pregnancy. However, few studies have evaluated the association of maternal weight changes before pregnancy and fetal growth. Most human studies on this topic have addressed the impact of inter-pregnancy weight changes [15-17]. Epidemiological data have shown that in obese women, weight gain before pregnancy is associated with an increased risk of complications during pregnancy and macrosomia at birth [15-19]. Further studies have suggested decreased risk of LGA with weight loss between 2 pregnancies or after bariatric surgery for obese women $[15,16,20]$. However, increased risk of small for gestational age (SGA) has also been observed in association with bariatric surgery before pregnancy [21,22]. Weight loss before pregnancy could help reduce pregnancy and perinatal complications in overweight and obese women, but studies are needed to ensure that it has no harmful side effects. Conversely, women who were underweight at conception showed increased risk of preterm 
delivery; another study showed, for those who lost weight before pregnancy, a risk of fetal growth restriction and low infant birth weight $[23,24]$. Hence, the consequences for pregnancy outcomes of weight change before pregnancy may differ according to maternal BMI status at conception.

\section{Objective}

This study aimed to investigate the association between maternal weight variation in the year before pregnancy and birth weight in a national birth cohort study in France. We hypothesized that maternal weight variation before pregnancy could be involved in the mechanisms programming fetal growth. Weight loss before pregnancy could be clinically relevant in overweight and obese women but not in normal-weight women, so we a priori stratified our analysis according to weight status at the beginning of pregnancy.

\section{Methods}

This study is reported as per the Strengthening the Reporting of Observational Studies in Epidemiology (STROBE) guideline (S1 STROBE guideline checklist). A brief analysis plan was written and approved before starting statistical analyses (S1 Protocol).

\section{Study}

The ELFE study (Étude Longitudinale Française depuis l'Enfance) is a French national longitudinal birth cohort with more than 18,000 children included at birth. The rationale and design of the ELFE cohort were previously detailed [25]. Recruitment took place on 25 selected days during 4 periods in 2011. The inclusion criteria were birth at 33 weeks' amenorrhea or more, singleton or twin birth, and mother $>18$ years, who gave informed consent and did not plan to leave metropolitan France within 3 years. Participation in the cohort was proposed to women who gave birth in 349 maternity hospitals randomly selected among the 544 public and private maternity hospitals in metropolitan France. Among eligible mothers, 51\% agreed to participate $(N=18,040)$. The ELFE study was approved by an ethics committee (Comité de Protection des Personnes), the national committee on information concerning health research (Comité Consultatif sur le Traitement de l'Information en Matière de Recherche dans le domaine de la Santé), and the data protection authority (Commission Nationale de l'Informatique et des Libertés).

\section{Data collection}

We used data collected from the following sources in the maternity wards after birth: medical records (S1 Questionnaire), face-to-face interviews (S2 Questionnaire), and self-administered questionnaires ( $\mathrm{S} 3 \mathrm{Questionnaire).} \mathrm{A} \mathrm{telephone} \mathrm{questionnaire} \mathrm{answered} \mathrm{by} \mathrm{the} \mathrm{parents} \mathrm{at} 2$ months after birth was also used to complete information on sociodemographic characteristics.

Preconception weight variations. The maternal self-administered questionnaire collected information on preconception weight variations during the year before pregnancy, with 5 possible answers: gain of $>5 \mathrm{~kg}$, gain of 2 to $5 \mathrm{~kg}$, stable, loss of 2 to $5 \mathrm{~kg}$, and loss of $>5 \mathrm{~kg}$. We classified weight variation into 3 groups: weight loss $>5 \mathrm{~kg}$; stable weight or moderate variation (absolute weight change $\leq 5 \mathrm{~kg}$ ) (subsequently termed "stable weight"); and weight gain $>5 \mathrm{~kg}$ or both a loss $>5 \mathrm{~kg}$ and gain $>5 \mathrm{~kg}$ (subsequently termed "weight gain"). We grouped stable weight and moderate variation (absolute weight change $\leq 5 \mathrm{~kg}$ ) in a single "stable weight" category because birth weight was not significantly different between the different 
groups. Some women indicated both a weight gain $>5 \mathrm{~kg}$ and a loss $>5 \mathrm{~kg}$ in the year before pregnancy. Because these women were too few $(N=191)$ to be considered a separate group, they were grouped with the "weight gain" category.

The women also declared whether they had followed a restrictive diet to lose weight during the year before pregnancy.

Fetal growth and anthropometric measures. We collected gestational age, child sex, and anthropometry at birth from medical records. $z$-Scores for birth weight were calculated according to French Audipog reference [26] taking into account gestational age and sex at birth. We also wanted to give a clinical interpretation of the results and investigated birth weight $z$-score in the categories SGA ( $<10$ th percentile), appropriate for gestational age (10th to 90 th percentile), and LGA ( $>90$ th percentile).

Maternal variables. Sociodemographic data collected included maternal age (continuous), parity, education level (lower secondary, upper secondary, post-secondary, or tertiary education) according to the International Standard Classification of Education [27], activity status at the beginning of pregnancy (staying at home [including housewife, parental leave, unemployment] versus employed or student), living with a partner (yes versus no), place of birth (born in France versus other country), and pregnancy caregiver (gynecologist, midwife, general practitioner or none, or multiple professionals).

Health-related variables collected included health insurance coverage (regular versus related to precarious situations), smoking before and during pregnancy (yes versus no), and GWG (continuous). Pre-pregnancy BMI was calculated as weight $(\mathrm{kg})$ divided by height squared $\left(\mathrm{m}^{2}\right)$ and classified into 4 categories according to World Health Organization thresholds: underweight, $<18.5 \mathrm{~kg} / \mathrm{m}^{2}$; normal weight, 18.5 to $<25.0 \mathrm{~kg} / \mathrm{m}^{2}$; overweight, 25.0 to $<30.0 \mathrm{~kg} / \mathrm{m}^{2}$; and obesity, $\geq 30.0 \mathrm{~kg} / \mathrm{m}^{2}$. Maternal GWG was calculated as measured weight at the end of pregnancy minus weight before pregnancy as reported by mothers.

Preexisting type 1 or 2 diabetes or gestational diabetes and medical history of chronic hypertension or gestational hypertension were retrieved from medical records. In addition, medical history of chronic severe disease or disabilities recorded in the medical record was collected by the research assistant and coded according to the International Classification of Diseases, 10th revision.

\section{Population selection}

Among the 18,040 mothers, who gave birth to 18,328 infants included in the study, 56 withdrew from the study and asked for data deletion. We excluded 574 twins from the analyses, as well as 175 and 59 mothers with missing medical records and face-to-face interviews, respectively. Finally, we also excluded 842 women with a medical history before pregnancy that may result in weight changes (history of metabolic or endocrine disease, thyroid disease, autoimmune disease, depression, psychological disorder such as anorexia, epilepsy, digestive disease, Crohn disease, bariatric surgery, infectious disease, cancer or congenital anomaly, chronic hypertension, or type 1 or 2 diabetes). Finally, 227 records with missing data on BMI, a key stratification variable, were not considered in the analysis. Fig 1 summarizes the steps of the population selection, which resulted in data for 16,395 women included in the analysis.

\section{Missing data imputation process}

Most variables had less than 3\% missing data, except for weight changes before pregnancy (collected by the self-administered questionnaire), which had about 13\% missing data. Missing data for exposures, outcomes, and confounders were imputed using the SAS "MI" procedure. We compared women with and without a completed self-administered questionnaire and 


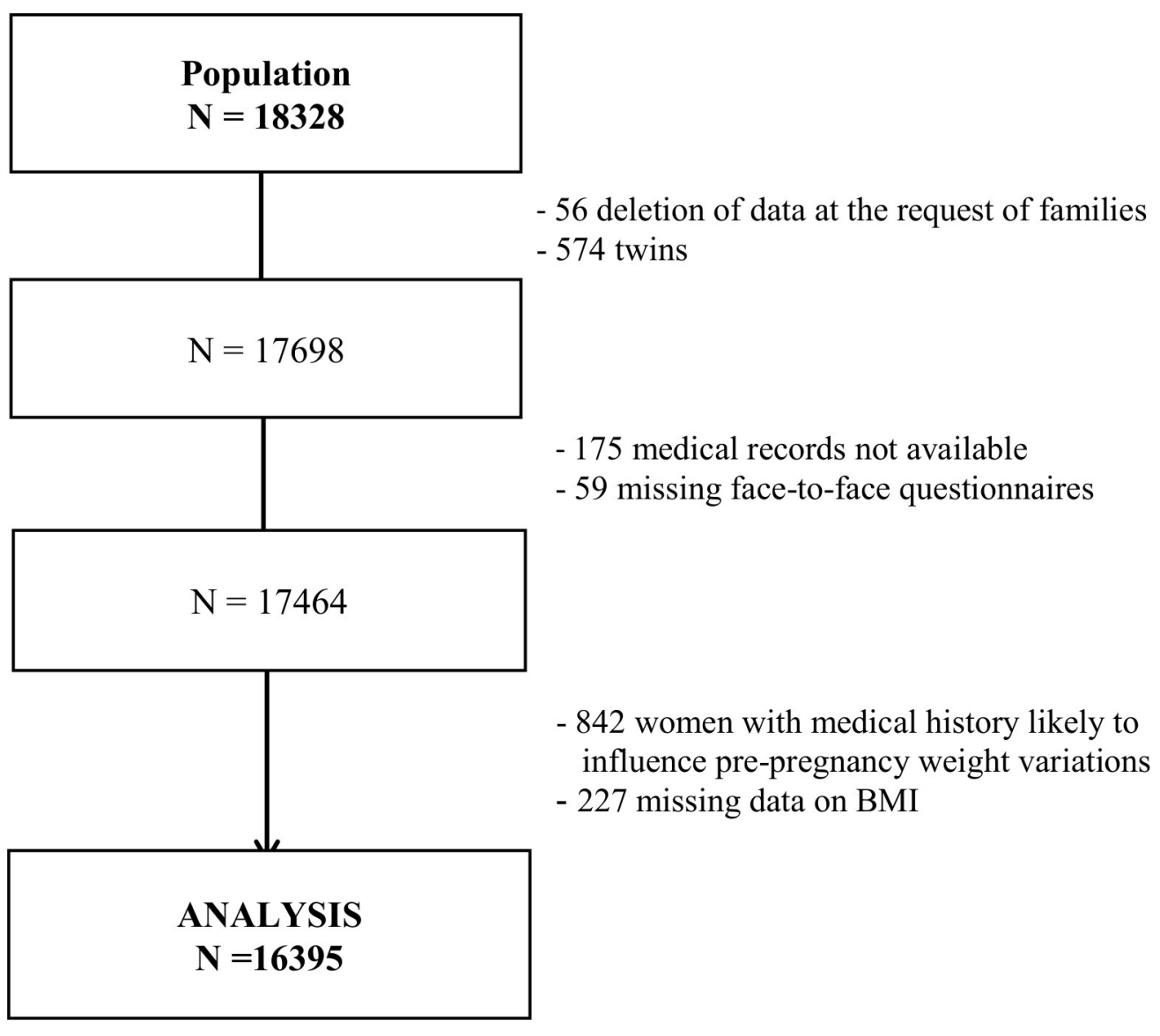

Fig 1. Selection of women for analysis.

https://doi.org/10.1371/journal.pmed.1002871.g001

included all variables with significant difference in the imputation process (sociodemographic factors, birth characteristics, and maternal medical history). We generated 5 imputed datasets using the fully conditional specification method (S1 Table). The results of different imputed datasets were combined using the SAS "MI analyse" procedure, and standard errors were calculated using Rubin's rules, which take into account the variability between the multiple regressions in imputed datasets $[28,29]$.

\section{Statistical analysis}

Characteristics of mothers and their children are described with mean \pm SD and frequency (\%) before imputation. We compared sociodemographic characteristics between women with different weight variations before pregnancy by chi-squared test for categorical variables and ANOVA for continuous variables, before imputation. Linear regression analyses were used to investigate the association between weight changes in the year before pregnancy and birth weight $z$-score (hereafter called "birth weight"). Logistic regression was used for analyzing the risk of SGA (SGA/no SGA) and LGA (LGA/no LGA). Women in the weight loss or gain group were compared to women with stable weight. We adjusted our analysis for the following confounders after careful selection based on directed acyclic graphs [30]: level of education, maternal age, smoking before and during pregnancy, place of birth, parity, health insurance coverage, and activity status. We stratified our analysis on weight status (i.e., maternal BMI at conception: $<25$ versus $\geq 25 \mathrm{~kg} / \mathrm{m}^{2}$ ) for clinical considerations because weight loss before 
pregnancy could be advised and beneficial in overweight and obese women but not in normalweight or underweight women. The interaction between weight variation before pregnancy and weight status on birth weight was significant (complete-case analysis, $p=0.003$ ). We additionally adjusted for BMI before pregnancy as a continuous variable within the $2 \mathrm{BMI}$ categories. All analyses were performed with SAS version 9.3. $p<0.05$ was considered statistically significant.

Mediation analysis. To address our mediation hypothesis, we used the method developed by MacKinnon et al. [31,32] (Fig 2). We hypothesized that GWG, which was associated with both the exposure (weight variation before pregnancy) and the dependent variable (birth weight), could be on the causal pathway. Indeed, we previously reported in the ELFE cohort that weight loss before pregnancy was associated with increased average weight gain during pregnancy whatever the BMI category before pregnancy (path $a$ in Fig 2) [33]. Mediation analyses were stratified by the BMI at conception categories $<25$ and $\geq 25 \mathrm{~kg} / \mathrm{m}^{2}$. The association between weight change (independent variable) and birth weight (dependent variable) adjusted for level of education, maternal age, smoking before and during pregnancy, place of birth, parity, health insurance coverage, activity status, and BMI corresponds to the total effect (path $c$ in Fig 2). The direct effect, or non-mediated effect (path $c^{\prime}$ ), is the effect of preconception weight change on birth weight via causal pathways other than influence on GWG, while the indirect effect is the effect that operates via the effect on GWG. The coefficient $b$ relates the mediator to the dependent variable adjusted for the independent variable.

The product $a \times b$ corresponds to the mediation, or indirect, effect, which we tested by the significance of the Sobel test. For $95 \%$ standard normal confidence limits of the indirect effect, a critical value of 1.96 was used for the standard error [34].

Complementary analysis. To reinforce the validity of our results, we performed several additional analyses. We also stratified our analyses by restricting the group of women who lost weight before pregnancy to (1) those who declared dieting before pregnancy or (2) those who
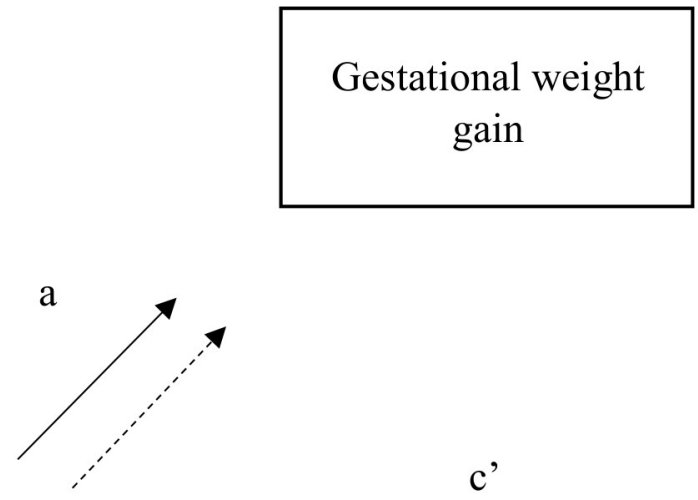

Weight loss or weight gain before pregnancy / stable weight

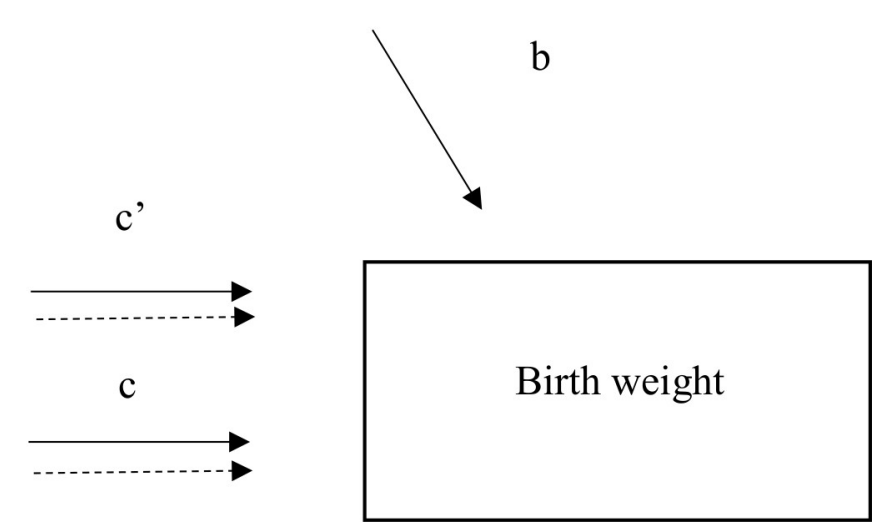

Fig 2. Mediator model. $a$ is the association between weight variation and the potential mediator, gestational weight gain. $b$ is the association between the potential mediator and the outcome variable, birth weight, adjusted for weight variation before pregnancy. $a \times b$ is the indirect effect. $c$ is the total effect: overall association between weight variation and the outcome variable. $c^{\prime}$ is the direct effect (nonmediated effect) adjusted for the mediator variable.

https://doi.org/10.1371/journal.pmed.1002871.g002 
lost weight for another unspecified reason (not related to severe illness). We hypothesized that women who lost weight secondary to intentional restriction of food intake would be more exposed to weight regain after the restriction cessation that generally occurs with the start of pregnancy.

Another complementary analysis consisted of excluding women who gave birth to a child within the 2 years preceding the studied pregnancy. Indeed, in this subgroup, women experiencing physiological weight changes related to the previous pregnancy might have been classified, depending on the date of pregnancy, in the weight gain or weight loss category in the year before pregnancy.

Another concern is that GWG includes the baby's weight. Therefore, the mediating effect of GWG could be overestimated, which would influence our estimate of the direct effect of weight change before pregnancy on birth weight. To explore this possibility, we studied, in a complementary analysis, the mediating effect of a variable called "maternal GWG," calculated by subtracting child's birth weight from GWG. Because the amount of GWG depends also on pregnancy duration, we performed a sensitivity analysis excluding premature birth.

Smoking behavior before and during pregnancy could modify the effect of weight variation before pregnancy on birth weight because many women could use smoking to restrict their appetite or weight gain before pregnancy. Therefore, we performed a complementary analysis restricted to women who did not smoke before and during pregnancy.

Finally, we re-ran all the analyses restricted to complete cases without missing data for exposure, outcome, and covariates.

\section{Results}

\section{Population characteristics}

The characteristics of the 16,395 women included in the analysis are summarized in Table 1 for the whole sample and by weight status, before multiple imputation of missing data. The women were mainly born in France (87\%) and were employed or students (81\%). More than $42 \%$ smoked before pregnancy, and $26 \%$ were overweight or obese.

\section{Statistical analysis}

Univariate analysis. Women with weight loss before pregnancy more frequently stayed at home $(20 \%)$ as compared with women with stable weight. We observed a significant difference between the 3 groups of weight variation before pregnancy in terms of smoking behavior $(p<$ 0.01 . Women who lost weight before pregnancy were more often smokers before pregnancy, and the proportion of these women who stopped smoking during pregnancy was about $26 \%$ and was greater than that for women with stable weight or weight gain before pregnancy. Results were similar whatever the weight status at conception. Overall, $57 \%$ of women with weight loss before pregnancy declared following a restrictive diet during the year before pregnancy (S2 Table).

Comparison of women by weight trajectory before pregnancy. Consistent with what was reported in a previous study of the ELFE cohort [33], weight loss and weight gain before pregnancy were associated with increased GWG after adjustment for confounders and BMI at conception. For women with BMI $<25 \mathrm{~kg} / \mathrm{m}^{2}$ at conception, those with weight loss before pregnancy gained more than 2 additional kilograms during pregnancy $(\beta=2.20$ [95\% CI 1.79; 2.61 ], $p<0.01$ ) than women with stable weight before pregnancy ( $\mathrm{S} 3 \mathrm{Table}$ ). Weight gain during pregnancy was also higher among women with weight gain before pregnancy than those with stable weight ( $\beta=1.12$ [95\% CI 0.79; 1.45], $p<0.01$ ). For women with BMI $\geq 25 \mathrm{~kg} / \mathrm{m}^{2}$ at conception, those with weight loss before pregnancy gained about $2.8 \mathrm{~kg}$ more during 
Table 1. Description of the ELFE population $(N=16,395)$ after excluding women with a medical history or missing data on body mass index (BMI), in the whole sample and by BMI at the beginning of pregnancy.

\begin{tabular}{|c|c|c|c|c|}
\hline Characteristic & $\begin{array}{l}\text { Missing data } \\
N(\%)\end{array}$ & $\begin{array}{l}\text { Population } \\
(N=16,395)\end{array}$ & $\begin{array}{l}\text { BMI }<25 \mathrm{~kg} / \mathrm{m}^{2} \\
(N=12,058)\end{array}$ & $\begin{array}{l}\text { BMI } \geq 25 \mathrm{~kg} / \mathrm{m}^{2} \\
(N=4,337)\end{array}$ \\
\hline \multicolumn{5}{|l|}{ Mother } \\
\hline Maternal age (years), $n(\%)$ & $4(0.02)$ & & & \\
\hline$\leq 25$ & & $2,225(13.6)$ & $1,582(13.1)$ & $643(14.8)$ \\
\hline $26-35$ & & $11,085(67.6)$ & $8,273(68.6)$ & $2,812(64.8)$ \\
\hline$>35$ & & $3,081(18.8)$ & $2,199(18.2)$ & $882(20.3)$ \\
\hline Born in France, $n(\%)$ & $12(0.07)$ & $14,272(87.1)$ & $10,601(88.0)$ & $3,671(84.8)$ \\
\hline Maternal education, $n(\%)$ & $1(0.01)$ & & & \\
\hline Lower secondary & & $1,368(8.3)$ & $847(7.0)$ & $521(12.0)$ \\
\hline Upper secondary & & $5,711(34.8)$ & $3,841(31.9)$ & $1,870(43.1)$ \\
\hline Post-secondary & & $3,663(22.3)$ & $2,675(22.2)$ & $988(22.8)$ \\
\hline Tertiary & & $5,652(34.5)$ & $4,694(38.9)$ & $958(22.1)$ \\
\hline Activity status, $n(\%)$ & $351(2.1)$ & & & \\
\hline Employed or student & & $12,935(80.6)$ & $9,839(83.2)$ & $3,096(73.3)$ \\
\hline Staying at home & & $3,109(19.4)$ & $1,982(16.8)$ & $1,127(26.7)$ \\
\hline Health insurance coverage, $n(\%)$ & $55(0.3)$ & & & \\
\hline For precarious situations & & $1,343(8.2)$ & $853(7.1)$ & $490(11.4)$ \\
\hline$\underline{\text { Regular }}$ & & $14,997(91.8)$ & $11,170(92.9)$ & $3,827(88.6)$ \\
\hline Living with a partner, $n(\%)$ & $73(0.4)$ & $15,450(94.7)$ & $11,409(95.1)$ & $4,041(93.5)$ \\
\hline Smoking before pregnancy, $\boldsymbol{n}(\%)$ & $49(0.3)$ & $6,964(42.6)$ & $5,211(43.3)$ & $1,753(40.6)$ \\
\hline \multicolumn{5}{|l|}{ Pregnancy } \\
\hline Primiparous, $\boldsymbol{n}(\%)$ & $31(0.2)$ & $7,313(44.7)$ & $5,680(47.2)$ & $1,633(37.7)$ \\
\hline Pregnancy caregiver, $n(\%)$ & $112(0.7)$ & & & \\
\hline Gynecologist & & $10,718(65.8)$ & $7,958(66.4)$ & $2,760(64.1)$ \\
\hline Midwife & & $2,034(12.5)$ & $1,455(12.1)$ & $579(13.4)$ \\
\hline General practitioner or none & & $907(5.6)$ & $638(5.3)$ & $269(6.2)$ \\
\hline Multiple professionals & & $2,624(16.1)$ & $1,926(16.1)$ & $698(16.2)$ \\
\hline Smoking during pregnancy, $n(\%)$ & $104(0.6)$ & $3,281(20.1)$ & $2,446(20.4)$ & $835(19.4)$ \\
\hline Weight variation in the year before pregnancy, $\boldsymbol{n}(\%)$ & $2,102(12.8)$ & & & \\
\hline Weight loss & & $1,415(9.9)$ & $806(7.7)$ & $609(16.2)$ \\
\hline Stable weight & & $11,210(78.4)$ & $8,952(85.0)$ & $2,258(60.0)$ \\
\hline Weight gain & & $1,668(11.7)$ & $771(7.3)$ & $897(23.8)$ \\
\hline Restrictive diet before pregnancy, $n(\%)$ & $1,974(12.0)$ & $2,381(16.5)$ & $1,202(11.3)$ & $1,179(31.1)$ \\
\hline Pre-pregnancy BMI category & $0(0)$ & & & \\
\hline Underweight & & $1,292(7.9)$ & $1,292(10.7)$ & - \\
\hline Normal & & $10,766(65.7)$ & $10,766(89.3)$ & - \\
\hline Overweight & & $2,791(17.0)$ & - & $2,791(64.4)$ \\
\hline Obesity & & $1,546(9.4)$ & - & $1,546(35.6)$ \\
\hline Gestational weight gain $(\mathrm{kg})$, mean \pm SD & $114(0.7)$ & $13.2 \pm 5.5$ & $13.9 \pm 4.8$ & $11.2 \pm 7$ \\
\hline \multicolumn{5}{|l|}{ Newborn } \\
\hline Gestational age of birth (WA), mean \pm SD & $111(0.7)$ & $39.6 \pm 1.4$ & $39.6 \pm 1.4$ & $39.7 \pm 1.4$ \\
\hline Birth weight Audipog $z$-score ${ }^{\mathrm{a}}$, mean \pm SD & $322(2.0)$ & $0.08 \pm 1.0$ & $0.01 \pm 0.9$ & $0.27 \pm 1.0$ \\
\hline Birth weight category $^{\mathrm{b}}, n(\%)$ & $322(2.0)$ & & & \\
\hline Small for gestational age & & $1,280(8.0)$ & $1,012(8.6)$ & $268(6.3)$ \\
\hline Appropriate for gestational age & & $13,238(82.4)$ & $9,866(83.5)$ & $3,372(79.2)$ \\
\hline Large for gestational age & & $1,555(9.7)$ & $939(7.9)$ & $616(14.5)$ \\
\hline
\end{tabular}

${ }^{\mathrm{a}}$ Birth weight $z$-score according to the French Audipog reference [26].

${ }^{\mathrm{b}}$ Birth weight categories to assess fetal growth: small for gestational age ( $<10$ th percentile), appropriate for gestational age (10th to 90 th percentile), and large for gestational age ( $>90$ th percentile) according to the French Audipog reference.

WA, weeks' amenorrhea.

https://doi.org/10.1371/journal.pmed.1002871.t001 
pregnancy $(\beta=2.76$ [95\% CI 2.21; 3.32], $p<0.01)$ than women with stable weight before pregnancy. Also, women with weight gain before pregnancy had a persistent dynamic of excessive weight gain during pregnancy, resulting in $>1.6 \mathrm{~kg}$ higher GWG ( $\beta=1.61$ [95\% CI 1.12; 2.11], $p<0.01)$ compared with women with stable weight.

Association with birth weight $z$-score. For women with pre-pregnancy BMI $<25 \mathrm{~kg} / \mathrm{m}^{2}$, in multivariable models adjusted in particular for pre-pregnancy BMI, the difference in mean birth weight $z$-score was significantly increased for offspring of mothers with pre-pregnancy weight loss as compared with women with stable weight ( $\beta=0.08$ [95\% CI 0.02; 0.14], $p=$ 0.01 ) (Table 2). Pre-pregnancy weight loss was not significantly associated with the risk of SGA and LGA, although the risk of SGA was non-significantly decreased ( $\beta=0.78$ [95\% CI $0.58 ; 1.05], p=0.10$ ). Among women with pre-pregnancy BMI $\geq 25 \mathrm{~kg} / \mathrm{m}^{2}$, weight loss before pregnancy was not associated with birth weight for a given pre-pregnancy BMI. Offspring of mothers with pre-pregnancy weight gain had increased birth weight and risk of LGA, although not significantly $(\beta=1.19$ [95\% CI $0.94 ; 1.49], p=0.15)$.

\section{Mediation analysis}

For women with BMI $<25 \mathrm{~kg} / \mathrm{m}^{2}$ before pregnancy, increased GWG predicted increased birth weight ( $\beta=0.041$ [95\% CI 0.037; 0.044], $p<0.01$ ). The positive association between weight loss before pregnancy and birth weight (total effect) for a given pre-pregnancy BMI was fully mediated by the indirect effect of GWG, the direct effect being close to $0(\beta=-0.008$ [95\% CI -0.07; 0.05], $p=0.79$ ) (Fig 3).

For women with BMI $\geq 25 \mathrm{~kg} / \mathrm{m}^{2}$, increased GWG was also associated with increased birth weight ( $\beta=0.030$ [95\% CI 0.026; 0.036], $p<0.01$ ). The association between pre-pregnancy weight loss and birth weight was not significant, but when the model was adjusted for GWG, weight loss before pregnancy had a significant negative direct effect on birth weight ( $\beta=-0.11$ $[95 \% \mathrm{CI}-0.19 ;-0.03], p=0.01$ ) for a given pre-pregnancy BMI (Fig 4 ). We found no significant association between weight gain before pregnancy and birth weight in the 2 BMI groups. However, we observed a significant mediating effect of GWG.

Table 2. Association between weight variation in the year before pregnancy and birth weight in unadjusted and adjusted model stratified by $B M I(N=16,395)$.

\begin{tabular}{|c|c|c|c|c|c|c|}
\hline \multirow[t]{2}{*}{$\begin{array}{l}\text { Weight change during the year before } \\
\text { pregnancy }\end{array}$} & \multicolumn{2}{|c|}{$\begin{array}{l}\text { Birth weight } z \text {-score (Audipog), } \beta \\
\text { (95\% CI) }\end{array}$} & \multicolumn{2}{|c|}{$\begin{array}{l}\text { Small for gestational age }{ }^{\mathrm{a}} \text {, OR }(95 \% \\
\text { CI) }\end{array}$} & \multicolumn{2}{|c|}{$\begin{array}{l}\text { Large for gestational age }{ }^{\mathrm{a}}, \text { OR }(95 \% \\
\text { CI) }\end{array}$} \\
\hline & Unadjusted model & Adjusted model & Unadjusted model & Adjusted model & Unadjusted model & Adjusted model \\
\hline \multicolumn{7}{|l|}{$\mathrm{BMI}<25 \mathrm{~kg} / \mathrm{m}^{2}(N=12,058)$} \\
\hline Weight loss ${ }^{\mathrm{b}}$ & $0.14(0.08 ; 0.21)$ & $0.08(0.02 ; 0.14)$ & $0.71(0.53 ; 0.95)$ & $0.78(0.58 ; 1.05)$ & $1.15(0.89 ; 1.47)$ & $0.98(0.75 ; 1.26)$ \\
\hline Stable weight ${ }^{\mathrm{b}}$ & 0 (Ref) & 0 (Ref) & 0 (Ref) & 0 (Ref) & 0 (Ref) & 0 (Ref) \\
\hline Weight gain $^{\mathrm{b}}$ & $0.04(-0.04 ; 0.12)$ & $0.02(-0.06 ; 0.10)$ & $1.01(0.76 ; 1.33)$ & $0.98(0.74 ; 1.30)$ & $1.16(0.87 ; 1.54)$ & $1.09(0.81 ; 1.48)$ \\
\hline \multicolumn{7}{|l|}{$\mathrm{BMI} \geq 25 \mathrm{~kg} / \mathrm{m}^{2}(N=4,337)$} \\
\hline Weight loss ${ }^{c}$ & $-0.01(-0.09 ; 0.07)$ & $-0.02(-0.1 ; 0.06)$ & $1.14(0.80 ; 1.62)$ & $1.13(0.79 ; 1.61)$ & $1.00(0.77 ; 1.31)$ & $0.96(0.73 ; 1.26)$ \\
\hline Stable weight $^{\mathrm{c}}$ & 0 (Ref) & 0 (Ref) & 0 (Ref) & 0 (Ref) & 0 (Ref) & 0 (Ref) \\
\hline Weight gain $^{c}$ & $0.03(-0.05 ; 0.11)$ & $0.03(-0.05 ; 0.11)$ & $1.02(0.73 ; 1.42)$ & $0.96(0.67 ; 1.37)$ & $1.21(0.97 ; 1.51)$ & $1.19(0.94 ; 1.49)$ \\
\hline
\end{tabular}

Adjusted model adjusted for maternal education level, maternal age, smoking before and during pregnancy, place of birth, parity, health insurance coverage, activity status, and pre-pregnancy BMI.

${ }^{\text {a }}$ Small for gestational age ( $<10$ th versus $\geq 10$ th percentile) and large for gestational age ( $>90$ th versus $\leq 90$ th percentile) according to the French Audipog reference [26].

${ }^{\mathrm{b}}$ Minimum-maximum number of women in each category of weight variation before pregnancy depending on imputed tables: weight loss, 910-944; stable weight, 10,177-10,192; and weight gain, 923-956.

${ }^{c}$ Minimum-maximum number of women in each category of weight variation before pregnancy depending on imputed tables: weight loss, 690-703; stable weight, 2,543-2,564; and weight gain, 1,072-1,097.

https://doi.org/10.1371/journal.pmed.1002871.t002 


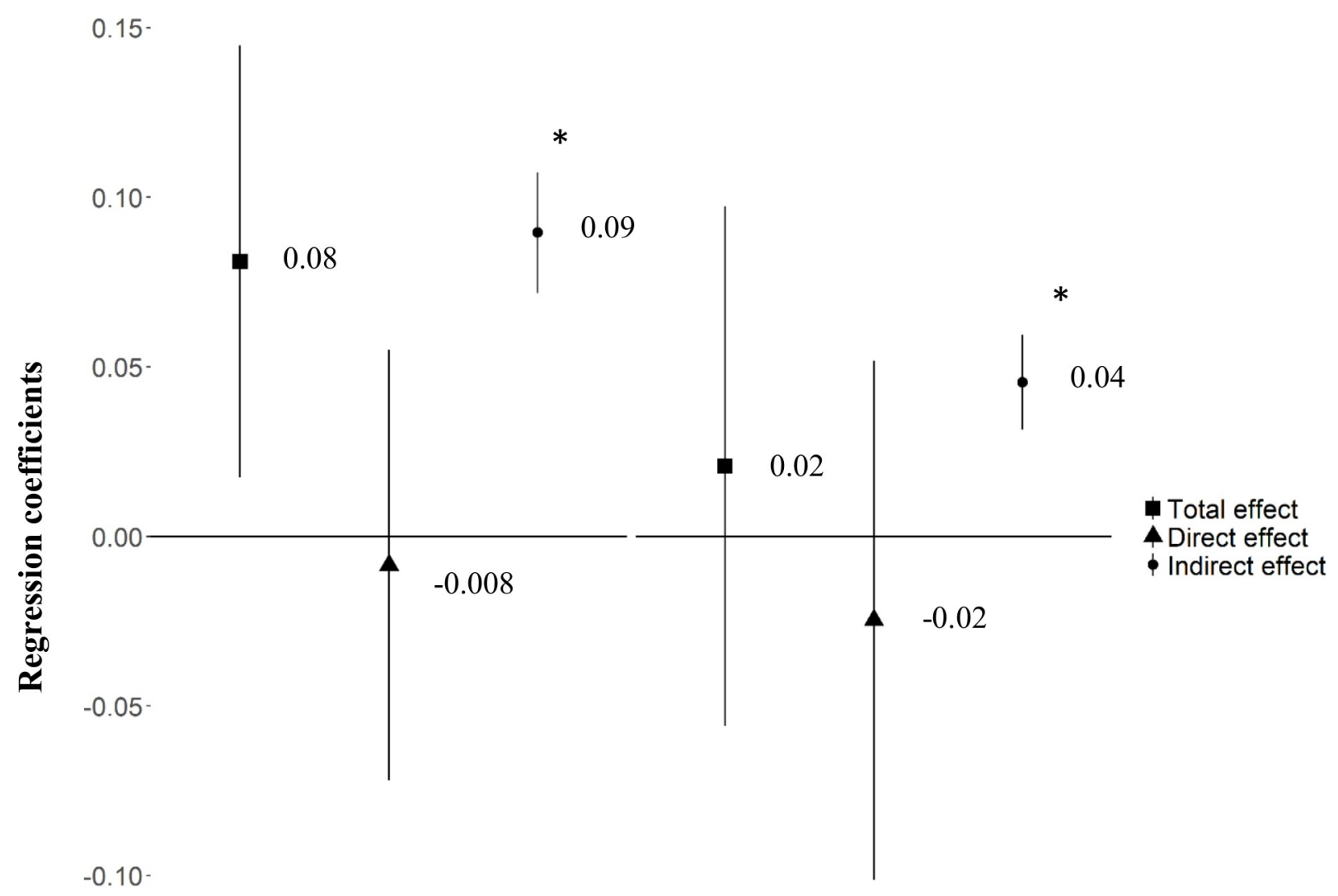

$-0.15$

\section{Weight loss vs stable weight Weight gain vs stable weight}

Fig 3. Association between weight variation before pregnancy and birth weight mediated by gestational weight gain for women with prepregnancy BMI $<\mathbf{2 5} \mathbf{~ k g} / \mathbf{m}^{2}$. Effect size $\beta$ (95\% CI). All models were adjusted for maternal education level, maternal age, smoking before and during pregnancy, place of birth, parity, health insurance coverage, activity status, and pre-pregnancy BMI. Birth weight $z$-score according to the French Audipog reference [26]. *Sobel test of indirect effect $p<0.001$.

https://doi.org/10.1371/journal.pmed.1002871.g003

The results were even stronger when we restricted the analysis to women with $\mathrm{BMI} \geq 30$ $\mathrm{kg} / \mathrm{m}^{2}(N=1,546)$, for a direct effect $(\beta=-0.19[95 \% \mathrm{CI}-0.33 ;-0.06], p<0.01)$ and negative total effect $(\beta=-0.12[95 \% \mathrm{CI}-0.26 ; 0.014], p=0.07)$. The direct effect was lower for overweight than obese women $(\beta=-0.06[95 \% \mathrm{CI}-0.17 ; 0.04], p=0.24)$, but we found a persistent and higher effect of GWG in this group ( $\beta=0.10$ [95\% CI 0.07; 0.13], $p<0.001)$.

\section{Complementary analyses}

Restrictive diet. Among women with pre-pregnancy BMI $\geq 25 \mathrm{~kg} / \mathrm{m}^{2}, 1,179$ had followed a restrictive diet in the year before pregnancy and 2,608 had not. The mediating effect of GWG was increased for women who had dieted and lost weight in the year before pregnancy $(\beta=$ 0.09 [95\% CI 0.05; 0.12], $p<0.001$ ) (S1 Fig).

Exclusion of women with a child born within 2 years before the current birth. In a complementary analysis, we excluded women who gave birth to a child within 2 years before 
0.15

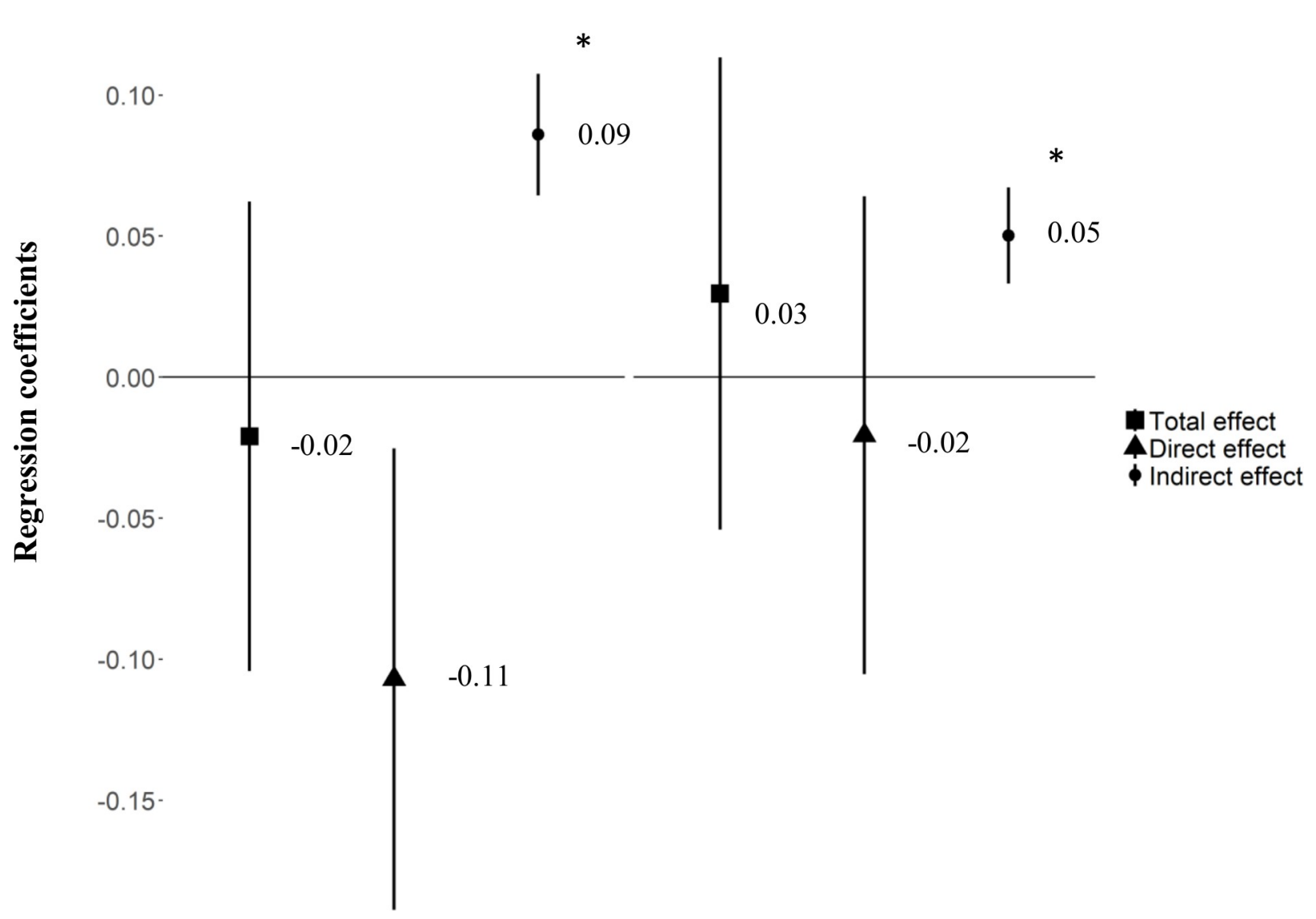

$-0.20$

\section{Weight loss vs stable weight Weight gain vs stable weight}

Fig 4. Association between weight variation before pregnancy and birth weight mediated by gestational weight gain for women with BMI $\geq 25 \mathrm{~kg} / \mathbf{m}^{2}$. Effect size $\beta$ (95\%CI). All models were adjusted on maternal education level, maternal age, smoking before and during pregnancy, place of birth, parity, health insurance coverage, activity status, and pre-pregnancy BMI. Birth weight $z$-score according to the French Audipog reference [26]. ${ }^{*}$ Sobel test of indirect effect $p<0.001$.

https://doi.org/10.1371/journal.pmed.1002871.g004

the current birth $(N=2,925)$ to assess how much our results were driven by weight changes associated with a recent pregnancy. The results were globally unchanged: Both weight loss and weight gain were associated with increased subsequent GWG in the 2 BMI groups. For women with BMI $\geq 25 \mathrm{~kg} / \mathrm{m}^{2}$, mediation analysis showed a negative direct effect of weight loss before pregnancy on birth weight, although of lower magnitude than in the whole sample ( $\beta=-0.07$ [95\% CI -0.17; 0.02], $p=0.11$ ).

Analysis replacing GWG with our estimate of maternal GWG. In the complementary analysis for women with BMI $\geq 25 \mathrm{~kg} / \mathrm{m}^{2}$ and weight loss before pregnancy, the mediating effect of maternal GWG was, as expected, reduced as compared with the main analysis ( $\beta=$ 0.06 [95\% CI $0.04 ; 0.08], p<0.01$ ), but the mediation analyses still found a negative direct effect of pre-pregnancy weight loss only slightly lower than that in the main analysis ( $\beta=-0.08$ [95\% CI $-0.16 ; 0.003], p=0.06$ ) (S2 Fig). 
Sensitivity analysis. In our analysis restricted to non-smoking women with $\mathrm{BMI}<25 \mathrm{~kg}$ / $\mathrm{m}^{2}(N=6,744)$, we found no association (total effect) between weight loss before pregnancy and birth weight $(\beta=0.02[95 \% \mathrm{CI}-0.07 ; 0.11])$. For those with BMI $\geq 25 \mathrm{~kg} / \mathrm{m}^{2}(N=2,533)$, the direct effect of pre-pregnancy weight loss on birth weight was slightly lower than in the main analysis ( $\beta=-0.09$ [95\% CI $-0.20 ; 0.03], p=0.03$, versus $\beta=-0.11$ [95\% CI $-0.19 ; 0.03]$ ), but we still observed a significant and persistent indirect effect of GWG ( $\beta=0.09$ [95\% CI $0.06 ; 0.12], p<0.001)$.

When we excluded premature birth in our sensitivity analysis, our results were unchanged for both BMI categories.

Complete-case analysis. Similar results were obtained from analyses restricted to complete cases as for analyses with imputed data. We also tested the analyses in participants without imputation of the outcome (birth weight) but with imputation of covariates, and the results were also unchanged.

\section{Discussion}

For women who were not overweight or obese at conception, we found a significant positive association between weight loss before pregnancy and birth weight that was totally mediated and explained by increased GWG. For women with overweight and obesity, we did not find an association between weight loss before pregnancy and birth weight. However, after taking into account GWG, weight loss before pregnancy had a negative direct effect on birth weight. GWG seemed to cancel out the expected effect on birth weight reduction of weight loss before pregnancy. For women with weight gain before pregnancy, GWG was increased during pregnancy and had a significant indirect effect on birth weight, but it did not translate into a significant total effect, and there was no direct association between weight gain before pregnancy and birth weight.

In contrast to our results, a previous French study evaluated weight change from age 20 years to pregnancy and showed that weight loss before pregnancy was associated with reduced fetal growth and with risk of SGA for women with BMI $<25 \mathrm{~kg} / \mathrm{m}^{2}$ [24]. In this study, prepregnancy weight loss reflected a much longer period before pregnancy and less directly reflected the consequence of a recent weight loss, especially in relation to increased GWG. In addition, the analyses were adjusted for GWG, and therefore only tested a direct effect of the previous weight trajectory without considering GWG as a mediator. An American study including more than 10,000 obese women found an increased risk of macrosomia for women with inter-pregnancy weight retention, but weight loss ( $\geq 2$ BMI units $\left.\left[\mathrm{kg} / \mathrm{m}^{2}\right]\right)$ between pregnancies was associated with reduced risk of LGA. However, excessive weight loss ( $>8 \mathrm{BMI}$ units) was related to increased SGA risk [16]. This finding highlights the need to also evaluate the risk of excessive weight loss before pregnancy for fetal development. Another study from a nationwide Swedish cohort also showed a dose-dependent increase in LGA risk with interpregnancy weight gain in overweight and obese women. The authors recommended weight loss after a pregnancy in overweight and obese women as well as prevention of weight gain before pregnancy for women with normal BMI [15]. After controlling for BMI at conception, we did not find an association between weight gain before pregnancy and birth weight. Women who self-reported weight gain in the year before conception showed a dynamic of excessive weight gain persisting over the pregnancy. However, their GWG was lower, on average, than that of women who lost weight before pregnancy. Obese women who gain weight before pregnancy are at risk of perinatal complications [15], and they might benefit from increased medical attention and monitoring during pregnancy. The differences between our 
study and results in the literature could also be explained by different time periods before pregnancy for considering weight change [35].

We have shown that a pre-pregnancy weight loss of $>5 \mathrm{~kg}$ is associated with reduced birth weight, after taking into account GWG. For a given pre-pregnancy BMI, overweight and obese women with a decreasing weight trajectory may have a better metabolic health and lipid profile at the start of pregnancy [36,37]. Lower frequency of glucose intolerance, hyperinsulinemia, or lipidemia may explain our observed direct effect on decreased birth weight, because all of these factors contribute to fetal growth [38,39]. Moreover, animal studies have shown an association of weight loss and low-fat diet in obese animals with better offspring outcomes, such as reduced fat mass and improved metabolic and hepatic function in offspring [40-42].

However, weight loss is accompanied by several physiological changes such as altered storage of energy and modified nutritional status and hormone pathways involved in the regulation of appetite, which can predispose to weight regain [43]. GWG is a unique and complex mechanism that can be influenced especially by maternal metabolism and placental function [44]. Smoking cessation is also a well-known risk factor for weight gain. In our study, $26 \%$ of women who smoked before pregnancy stopped smoking during pregnancy. When we restricted our analyses to overweight and obese women with no history of smoking, our main result was similar: We observed a negative direct effect of weight loss before pregnancy on birth weight and a positive indirect effect of GWG.

These physiological conditions may facilitate the mechanisms of weight regain after caloric restriction. Other factors related to pregnancy such as a decrease in physical activity may also elicit weight regain.

The strengths of our study are the large number of women included and the availability of sociodemographic and medical data. We had information on the medical history of women and excluded women with diseases, psychological disorders, bariatric surgery, and metabolic status that could have affected weight change before pregnancy. The use of multiple imputation techniques limited bias due to missing data in variables of interest and confounders.

Among the limitations is the questionable accuracy of data reported by the women on their weight history before pregnancy. However, our analysis focused on large weight changes $( \pm 5$ $\mathrm{kg}$ ) in a recent period ( 1 year before pregnancy). The accuracy would be similar for information collected by a heath professional at the start of pregnancy, and we feel that our results are relevant to a clinical situation. Another limitation is that our information on the potential cause of weight loss is limited to the practice of a restrictive diet, and information on the type of diet and dieting period in the year before pregnancy was lacking. We could not study whether our observed direct effect of weight loss on birth weight was due to the weight change itself or the modification of the maternal lifestyle driving it.

Using total GWG, including the baby's weight, is also a study limitation. When adjusting for total GWG, we took out part of the association we were trying to assess between pre-pregnancy weight variation and birth weight. To circumvent this drawback, in a complementary analysis, we approached the maternal component of GWG by subtracting the child's birth weight from the total GWG. We assumed that although GWG also includes placenta weight and amniotic fluid, the main source of variability of GWG minus birth weight was the maternal component. The results from this complementary analysis were similar to those of the main analysis, which supports our interpretation of the results.

Finally, we did not have information on intermediate weight measurements during pregnancy, which prevented us from assessing weight gain for specific periods or trimesters. GWG is not linear across gestation, and the rate of weight gain is slower in the first trimester [45]. Distinct kinetic GWG may have differential impact on fetal growth [46,47]. 
Only live births are included in the ELFE cohort. If weight change in the year before pregnancy affects the probability of miscarriage or stillbirth, our results could be biased, probably by underestimating the effect of extreme weight changes on fetal growth. A selection bias could also be possible if there were associations between, on the one hand, both fetal growth and weight change before pregnancy and, on the other, the probability of inclusion in the ELFE cohort. Except for low maternal education level, which was controlled for, we could not see any obvious reason why weight change before pregnancy would influence the probability of inclusion.

\section{Conclusion}

Few studies have evaluated the association between pre-pregnancy weight variation and fetal development. Our results suggest that increased GWG after weight loss before pregnancy may obscure any beneficial effect on fetal growth. These results call for increased vigilance on GWG in women who lost weight or dieted before pregnancy.

\section{Supporting information}

S1 Fig. Association between weight loss before pregnancy and birth weight mediated by gestational weight gain for women with $B M I \geq 25 \mathrm{~kg} / \mathrm{m}^{2}$ who had followed a restrictive diet or not. Effect size $\beta(95 \% \mathrm{CI})$. All models were adjusted for maternal education level, maternal age, smoking before and during pregnancy, place of birth, parity, health insurance coverage, activity status, and pre-pregnancy BMI. Birth weight $z$-score according to the French Audipog reference [26]. ${ }^{*}$ Sobel test of indirect effect $p<0.001$. For women with BMI $\geq 25 \mathrm{~kg} /$ $\mathrm{m}^{2}$ before pregnancy, the minimum-maximum numbers of women with weight loss or stable weight before pregnancy depending on imputed tables are as follows: no restrictive dietweight loss, 208-208; stable weight, 1,767-1,770; with restrictive diet—weight loss, 404-407; stable weight, $494-497$.

(TIFF)

S2 Fig. Association between weight variation before pregnancy and birth weight $z$-score mediated by gestational weight gain for women with a pre-pregnancy BMI $\geq 25 \mathrm{~kg} / \mathrm{m}^{2}$. Sensitivity analysis removing birth weight from gestational weight gain $(N=4,337)$. Effect size $\beta$ (95\% CI). All models were adjusted for maternal education level, maternal age, smoking before and during pregnancy, place of birth, parity, health insurance coverage, activity status, and pre-pregnancy BMI. Birth weight $z$-score according to the French Audipog reference [26]. * Sobel test of indirect effect $p<0.001$.

S1 Protocol. Description of the prospective analysis plan. (DOCX)

S1 Questionnaire. Maternity medical record. (PDF)

S2 Questionnaire. Maternity mother interview. (PDF)

S3 Questionnaire. Maternal weight variation.

(DOCX)

S1 STROBE guideline checklist.

(DOC) 
S1 Table. Details of the method used for multiple imputation. * Fully conditional specification method. ${ }^{* *}$ Percent interval of missing data for the different $z$-scores of fetal growth in the second and third trimester.

(DOCX)

S2 Table. Characteristics of women by weight variation before pregnancy $(N=14,293)$ before imputation, after excluding women with a medical history and missing data for BMI. Data are percent $(n)$ or mean \pm SD. ${ }^{*}$ By chi-squared test comparing the 3 groups of weight variation or ANOVA for continuous variables. (DOCX)

S3 Table. Association between weight variation before pregnancy and gestational weight gain by BMI category. Adjusted model: linear regression adjusted for maternal education level, maternal age, smoking before and during pregnancy, place of birth, parity, health insur-

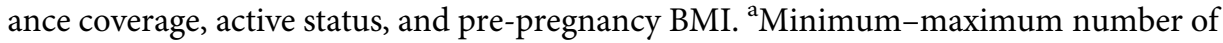
women in each category of weight variation before pregnancy depending on imputed tables: weight loss, 910-944; stable weight, 10,177-10,192; and weight gain, 923-956. ' ${ }^{\mathrm{b}}$ Minimummaximum number of women in each category of weight variation before pregnancy depending on imputed tables: weight loss, 690-703; stable weight, 2,543-2,564; and weight gain, $1,072-1,097$.

(DOCX)

\section{Acknowledgments}

The ELFE study is a joint project between the French Institute for Demographic Studies (INED) and the National Institute of Health and Medical Research (INSERM), in partnership with the French blood transfusion service (Établissement français du sang [EFS]), Santé publique France, the National Institute of Statistics and Economic Studies (INSEE), the Direction générale de la santé (part of the Ministry of Social Affairs and Health), the Direction générale de la prévention des risques (Ministry of the Environment), the Direction de la recherche, des études, de l'évaluation et des statistiques (Ministry of Social Affairs and Health), the Département des études, de la prospective et des statistiques (Ministry of Culture), and the Caisse nationale des allocations familiales, with the support of the Ministry of Higher Education, Research, and Innovation and the Institut national de la jeunesse et de l'éducation populaire.

We thank the members of the ELFE INED-INSERM-EFS joint unit and, above all, the families involved in the ELFE cohort, without whom this study would not have been possible.

\section{Author Contributions}

Conceptualization: Marion Lecorguillé, Madalina Jacota, Marie-Aline Charles, Barbara Heude.

Data curation: Blandine de Lauzon-Guillain, Marie Cheminat, Marie-Aline Charles, Barbara Heude.

Formal analysis: Marion Lecorguillé, Barbara Heude.

Funding acquisition: Marion Lecorguillé, Marie-Aline Charles, Barbara Heude.

Investigation: Marie Cheminat, Marie-Aline Charles, Barbara Heude.

Methodology: Marion Lecorguillé, Anne Forhan, Marie-Aline Charles, Barbara Heude.

Project administration: Marie-Aline Charles. 
Resources: Marie-Aline Charles.

Software: Marion Lecorguillé, Anne Forhan.

Supervision: Marie-Aline Charles, Barbara Heude.

Validation: Blandine de Lauzon-Guillain, Marie-Aline Charles, Barbara Heude.

Visualization: Marion Lecorguillé.

Writing - original draft: Marion Lecorguillé.

Writing - review \& editing: Marion Lecorguillé, Madalina Jacota, Blandine de Lauzon-Guillain, Anne Forhan, Marie-Aline Charles, Barbara Heude.

\section{References}

1. Deierlein AL, Siega-Riz AM, Adair LS, Herring AH. Effects of pre-pregnancy body mass index and gestational weight gain on infant anthropometric outcomes. J Pediatr. 2011; 158:221-6. https://doi.org/10. 1016/j.jpeds.2010.08.008 PMID: 20863516

2. Yu Z, Han S, Zhu J, Sun X, Ji C, Guo X. Pre-pregnancy body mass index in relation to infant birth weight and offspring overweight/obesity: a systematic review and meta-analysis. PLoS ONE. 2013; 8(4): e61627. https://doi.org/10.1371/journal.pone.0061627 PMID: 23613888

3. Ovesen $\mathrm{P}$, Rasmussen $\mathrm{S}$, Kesmodel U. Effect of prepregnancy maternal overweight and obesity on pregnancy outcome. Obstet Gynecol. 2011; 118:305-12. https://doi.org/10.1097/AOG. Ob013e3182245d49 PMID: 21775846

4. Dabelea D, Mayer-Davis EJ, Lamichhane AP, D'Agostino RB, Liese AD, Vehik KS, et al. Association of intrauterine exposure to maternal diabetes and obesity with type 2 diabetes in youth: the SEARCH Case-Control Study. Diabetes Care. 2008; 31:1422-6. https://doi.org/10.2337/dc07-2417 PMID: 18375420

5. McMillen IC, MacLaughlin SM, Muhlhausler BS, Gentili S, Duffield JL, Morrison JL. Developmental origins of adult health and disease: the role of periconceptional and foetal nutrition. Basic Clin Pharmacol Toxicol. 2008; 102:82-9. https://doi.org/10.1111/j.1742-7843.2007.00188.x PMID: 18226059

6. Kapadia MZ, Park CK, Beyene J, Giglia L, Maxwell C, McDonald SD. Weight loss instead of weight gain within the guidelines in obese women during pregnancy: a systematic review and meta-analyses of maternal and infant outcomes. PLoS ONE. 2015; 10(7):e0132650. https://doi.org/10.1371/journal. pone.0132650 PMID: 26196130

7. Rasmussen KM, Catalano PM, Yaktine AL. New guidelines for weight gain during pregnancy: what obstetrician/gynecologists should know. Curr Opin Obstet Gynecol. 2009; 21:521-6. https://doi.org/10. 1097/GCO.0b013e328332d24e PMID: 19809317

8. Goldstein RF, Abell SK, Ranasinha S, Misso M, Boyle JA, Black MH, et al. Association of gestational weight gain with maternal and infant outcomes. JAMA. 2017; 317:2207-25. https://doi.org/10.1001/ jama.2017.3635 PMID: 28586887

9. Hanson M, Barker M, Dodd JM, Kumanyika S, Norris S, Steegers E, et al. Interventions to prevent maternal obesity before conception, during pregnancy, and post partum. Lancet Diabetes Endocrinol. 2017; 5:65-76. https://doi.org/10.1016/S2213-8587(16)30108-5 PMID: 27743974

10. Agha M, Agha RA, Sandall J, Sandell J. Interventions to reduce and prevent obesity in pre-conceptual and pregnant women: a systematic review and meta-analysis. PLoS ONE. 2014; 9(5):e95132. https:// doi.org/10.1371/journal.pone.0095132 PMID: 24827704

11. Poston L, Bell R, Croker H, Flynn AC, Godfrey KM, Goff L, et al. Effect of a behavioural intervention in obese pregnant women (the UPBEAT study): a multicentre, randomised controlled trial. Lancet Diabetes Endocrinol. 2015; 3:767-77. https://doi.org/10.1016/S2213-8587(15)00227-2 PMID: 26165396

12. Dodd JM, Turnbull D, McPhee AJ, Deussen AR, Grivell RM, Yelland LN, et al. Antenatal lifestyle advice for women who are overweight or obese: LIMIT randomised trial. BMJ. 2014; 348:g1285. https://doi. org/10.1136/bmj.g1285 PMID: 24513442

13. Parat $S$, Nègre V, Baptiste $A$, Valensi $P$, Bertrand A-M, Chollet $C$, et al. Prenatal education of overweight or obese pregnant women to prevent childhood overweight (the ETOIG study): an open-label, randomized controlled trial. Int J Obes (Lond). 2019; 43:362-73. https://doi.org/10.1038/s41366-0180205-z PMID: 30242235

14. Heude B, Thiébaugeorges O, Goua V, Forhan A, Kaminski M, Foliguet B, et al. Pre-pregnancy body mass index and weight gain during pregnancy: relations with gestational diabetes and hypertension, 
and birth outcomes. Matern Child Health J. 2012; 16:355-63. https://doi.org/10.1007/s10995-0110741-9 PMID: 21258962

15. Villamor E, Cnattingius S. Interpregnancy weight change and risk of adverse pregnancy outcomes: a population-based study. Lancet. 2006; 368:1164-70. https://doi.org/10.1016/S0140-6736(06)69473-7 PMID: 17011943

16. Jain AP, Gavard JA, Rice JJ, Catanzaro RB, Artal R, Hopkins SA. The impact of interpregnancy weight change on birthweight in obese women. Am J Obstet Gynecol. 2013; 208:205.e1-7. https://doi.org/10. 1016/j.ajog.2012.12.018 PMID: 23246318

17. Getahun D, Ananth CV, Peltier MR, Salihu HM, Scorza WE. Changes in prepregnancy body mass index between the first and second pregnancies and risk of large-for-gestational-age birth. Am J Obstet Gynecol. 2007; 196:530.e1-8. https://doi.org/10.1016/j.ajog.2006.12.036 PMID: 17547882

18. Knight-Agarwal CR, Williams LT, Davis D, Davey R, Cochrane $T$, Zhang H, et al. Association of BMI and interpregnancy BMI change with birth outcomes in an Australian obstetric population: a retrospective cohort study. BMJ Open. 2016; 6:e010667. https://doi.org/10.1136/bmjopen-2015-010667 PMID: 27165646

19. Wallace JM, Bhattacharya S, Campbell DM, Horgan GW. Inter-pregnancy weight change impacts placental weight and is associated with the risk of adverse pregnancy outcomes in the second pregnancy. BMC Pregnancy Childbirth. 2014; 14:40. https://doi.org/10.1186/1471-2393-14-40 PMID: 24450357

20. Hezelgrave NL, Oteng-Ntim E. Pregnancy after bariatric surgery: a review. J Obes. 2011; 2011:501939. https://doi.org/10.1155/2011/501939 PMID: 21785717

21. Yi X, Li Q, Zhang J, Wang Z. A meta-analysis of maternal and fetal outcomes of pregnancy after bariatric surgery. Int J Gynaecol Obstet. 2015; 130:3-9. https://doi.org/10.1016/j.ijgo.2015.01.011 PMID: 25863541

22. Willis $\mathrm{K}$, Lieberman $\mathrm{N}$, Sheiner $\mathrm{E}$. Pregnancy and neonatal outcome after bariatric surgery. Best Pract Res Clin Obstet Gynaecol. 2015; 29:133-44. https://doi.org/10.1016/j.bpobgyn.2014.04.015 PMID: 25225055

23. Han Z, Mulla S, Beyene J, Liao G, McDonald SD, Knowledge Synthesis Group. Maternal underweight and the risk of preterm birth and low birth weight: a systematic review and meta-analyses. Int J Epidemiol. 2011; 40:65-101. https://doi.org/10.1093/ije/dyq195 PMID: 21097954

24. Diouf I, Charles MA, Thiebaugeorges O, Forhan A, Kaminski M, Heude B, et al. Maternal weight change before pregnancy in relation to birthweight and risks of adverse pregnancy outcomes. Eur J Epidemiol. 2011; 26:789-96. https://doi.org/10.1007/s10654-011-9599-9 PMID: 21710259

25. Vandentorren $\mathrm{S}$, Bois $\mathrm{C}$, Pirus $\mathrm{C}$, Sarter $\mathrm{H}$, Salines $\mathrm{G}$, Leridon $\mathrm{H}$. Rationales, design and recruitment for the Elfe longitudinal study. BMC Pediatr. 2009; 9:58. https://doi.org/10.1186/1471-2431-9-58 PMID: 19772571

26. Mamelle N, Munoz F, Grandjean H. [Fetal growth from the AUDIPOG study. I. Establishment of reference curves.] J Gynecol Obstet Biol Reprod (Paris). 1996; 25:61-70.

27. Eurostat. International Standard Classification of Education (ISCED). Brussels: Eurostat; 2018 [cited 2019 Jul 27]. Available from: https://ec.europa.eu/eurostat/statistics-explained/index.php/International_ Standard_Classification_of_Education_(ISCED).

28. Dong Y, Peng C-YJ. Principled missing data methods for researchers. Springerplus. 2013; 2:222. https://doi.org/10.1186/2193-1801-2-222 PMID: 23853744

29. Sterne JAC, White IR, Carlin JB, Spratt M, Royston P, Kenward MG, et al. Multiple imputation for missing data in epidemiological and clinical research: potential and pitfalls. BMJ. 2009; 338:b2393. https:// doi.org/10.1136/bmj.b2393 PMID: 19564179

30. Textor J, Liskiewicz M. Adjustment criteria in causal diagrams: an algorithmic perspective. arXiv:12023764 [Preprint]. 2012 Feb 14 [cited 2019 Jul 23]. Available from: http://arxiv.org/abs/1202.3764.

31. MacKinnon DP, Fairchild AJ, Fritz MS. Mediation analysis. Annu Rev Psychol. 2007; 58:593-614. https://doi.org/10.1146/annurev.psych.58.110405.085542 PMID: 16968208

32. Mackinnon DP, Warsi G, Dwyer JH. A simulation study of mediated effect measures. Multivar Behav Res. 1995; 30:41. https://doi.org/10.1207/s15327906mbr3001_3 PMID: 20157641

33. Jacota $\mathrm{M}$. Variations pondérales pré-conceptionelles et gestationnelles: étude de leurs relations avec le diabète gestationnel et le développement de l'adiposité des enfants à 5-6 ans à partir des cohortes mère-enfant françaises EDEN et ELFE [thesis]. Paris: Paris-Saclay University; 2016.

34. MacKinnon DP, Fritz MS, Williams J, Lockwood CM. Distribution of the product confidence limits for the indirect effect: Program PRODCLIN. Behav Res Methods. 2007; 39:384. PMID: 17958149

35. Stephenson J, Heslehurst N, Hall J, Schoenaker DAJM, Hutchinson J, Cade JE, et al. Before the beginning: nutrition and lifestyle in the preconception period and its importance for future health. Lancet. 2018; 391:1830-41. https://doi.org/10.1016/S0140-6736(18)30311-8 PMID: 29673873 
36. Jensen MD, Ryan DH, Apovian CM, Ard JD, Comuzzie AG, Donato KA, et al. 2013 AHA/ACC/TOS guideline for the management of overweight and obesity in adults: a report of the American College of Cardiology/American Heart Association Task Force on Practice Guidelines and the Obesity Society. J Am Coll Cardiol. 2014; 63:2985-3023. https://doi.org/10.1016/j.jacc.2013.11.004 PMID: 24239920

37. Assali AR, Ganor A, Beigel Y, Shafer Z, Hershcovici T, Fainaru M. Insulin resistance in obesity: bodyweight or energy balance? J Endocrinol. 2001; 171:293-8. https://doi.org/10.1677/joe.0.1710293 PMID: 11691649

38. HAPO Study Cooperative Research Group, Metzger BE, Lowe LP, Dyer AR, Trimble ER, Chaovarindr U, et al. Hyperglycemia and adverse pregnancy outcomes. N Engl J Med. 2008; 358:1991-2002. https://doi.org/10.1056/NEJMoa0707943 PMID: 18463375

39. Di Cianni G, Miccoli R, Volpe L, Lencioni C, Ghio A, Giovannitti MG, et al. Maternal triglyceride levels and newborn weight in pregnant women with normal glucose tolerance. Diabet Med J Br Diabet Assoc. 2005; 22:21-5. https://doi.org/10.1111/j.1464-5491.2004.01336.x PMID: 15606686

40. Matusiak K, Barrett HL, Callaway LK, Nitert MD. Periconception weight loss: common sense for mothers, but what about for babies? J Obes. 2014; 2014:204295. https://doi.org/10.1155/2014/204295 PMID: 24804085

41. McCurdy CE, Bishop JM, Williams SM, Grayson BE, Smith MS, Friedman JE, et al. Maternal high-fat diet triggers lipotoxicity in the fetal livers of nonhuman primates. J Clin Invest. 2009; 119:323-35. https://doi.org/10.1172/JCI32661 PMID: 19147984

42. Rattanatray L, MacLaughlin SM, Kleemann DO, Walker SK, Muhlhausler BS, McMillen IC. Impact of maternal periconceptional overnutrition on fat mass and expression of adipogenic and lipogenic genes in visceral and subcutaneous fat depots in the postnatal lamb. Endocrinology. 2010; 151:5195-205. https://doi.org/10.1210/en.2010-0501 PMID: 20861234

43. Sumithran $P$, Proietto $J$. The defence of body weight: a physiological basis for weight regain after weight loss. Clin Sci (Lond). 2013; 124:231-41. https://doi.org/10.1042/CS20120223 PMID: 23126426

44. Institute of Medicine, National Research Council. Weight gain during pregnancy: reexamining the guidelines. Washington (DC): National Academies Press; 2009.

45. Hutcheon JA, Bodnar LM. Good practices for observational studies of maternal weight and weight gain in pregnancy. Paediatr Perinat Epidemiol. 2018; 32:152-60. https://doi.org/10.1111/ppe.12439 PMID: 29345321

46. Margerison-Zilko CE, Shrimali BP, Eskenazi B, Lahiff M, Lindquist AR, Abrams BF. Trimester of maternal gestational weight gain and offspring body weight at birth and age five. Matern Child Health J. 2012; 16:1215-23. https://doi.org/10.1007/s10995-011-0846-1 PMID: 21735140

47. Karachaliou M, Georgiou V, Roumeliotaki T, Chalkiadaki G, Daraki V, Koinaki S, et al. Association of trimester-specific gestational weight gain with fetal growth, offspring obesity and cardio-metabolic traits in early childhood. Am J Obstet Gynecol. 2015; 212:502.e1-14. https://doi.org/10.1016/j.ajog.2014.12. 038 PMID: 25557209 